University of New Hampshire

University of New Hampshire Scholars' Repository

Civil and Environmental Engineering

Scholarship

Civil and Environmental Engineering

7-23-2009

\title{
Effect of Humic Acid on Adsorption of Polychlorinated Biphenyls onto Organoclay
}

\author{
Bhawana Sharma \\ University of New Hampshire \\ Kevin H. Gardner \\ University of New Hampshire, kevin.gardner@unh.edu \\ Jeffrey S. Melton \\ University of New Hampshire, Jeffrey.Melton@unh.edu \\ Amy Hawkins \\ Naval Facilities Engineering Service Center \\ Gregory Tracey \\ Science Applications International Corporation
}

Follow this and additional works at: https://scholars.unh.edu/civeng_facpub

Part of the Civil and Environmental Engineering Commons

\section{Recommended Citation}

Sharma, B. K.H. Gardner, J. Melton, A. Hawkins, G. Tracey, "Effect of Humic Acid on Adsorption of Polychlorinated Biphenyls onto Organoclay," Environmental Engineering Science 26 (8):1279-1287 (2009).

This Article is brought to you for free and open access by the Civil and Environmental Engineering at University of New Hampshire Scholars' Repository. It has been accepted for inclusion in Civil and Environmental Engineering Scholarship by an authorized administrator of University of New Hampshire Scholars' Repository. For more information, please contact Scholarly.Communication@unh.edu. 


\title{
Effect of Humic Acid on Adsorption of Polychlorinated Biphenyls onto Organoclay
}

\author{
Bhawana Sharma, Kevin H. Gardner,, ${ }^{1, \star}$ Jeffrey Melton, Amy Hawkins, ${ }^{2}$ and Gregory Tracey ${ }^{3}$ \\ ${ }^{1}$ Environmental Research Group, University of New Hampshire, Durham, New Hampshire. \\ ${ }^{2}$ Naval Facilities Engineering Service Center, Port Hueneme, California. \\ ${ }^{3}$ Science Applications International Corporation, Newport, Rhode Island.
}

Received: July 22, 2008 Accepted in revised form: May 19, 2009

\begin{abstract}
Mitigation of risks stemming from contaminated sediments in freshwater and estuarine environments remains an important challenge to the field of environmental science and engineering. Capping sediments with reactive materials is one approach that has recently been the subject of research and development. This research evaluated the use of organoclay as a sorbent in a reactive cap for in situ remediation of contaminated sediments, and provides an original contribution by presenting the sorption characteristics of individual polychlorinated biphenyls (PCB) congeners in the presence of high concentrations of humic acids typical of sediment porewater environments. Sorption of coplanar and noncoplanar PCBs on three commercially available organoclays was studied in this work. Studies were conducted to evaluate the kinetics of adsorption of PCBs on organoclay and to determine the effect of humic acid on the kinetics of adsorption. Isotherm studies were conducted to determine the adsorption affinity of PCBs for organoclays in the presence and absence of humic acid. Studies showed a 45 to $96 \%$ reduction in the sorption affinity for organoclays after preloading with high concentrations of humic acid, depending both on the congener and the composition of organoclay. Desorption of PCBs upon addition of humic acid after PCBs were equilibrated with organoclay was statistically significant, although the magnitude of the effect was much smaller than that observed from preloading of humic acid.
\end{abstract}

Key words: reactive cap sorbent; organoclay; PCBs; humic acid

\section{Introduction}

$\mathbf{H}$ YDROPHOBIC ORGANIC CONTAMINANTS (HOCs) such as polychlorinated biphenyls (PCBs) are of great concern in riverine and marine environments due to their particle association, persistence, and bioaccumulation [National Research Council (NRC), 2001, 2003). PCBs, which are a group of 209 congeners, are listed at number five in the CERCLA 2007 priority list of hazardous substances (ATSDR, 2007). This listing is based on the toxicity of the compounds, their frequency of occurrence in national priority list (NPL) sites, and their potential of exposure to human beings. Strong sorption on sediments and slow degradation make PCBs persistent and difficult to remediate. Currently, dredging, monitored natural recovery, and in situ capping are the demonstrated remediation options for contaminated sediments. Reactive capping, which refers to the construction of a barrier layer comprised of materials that can degrade or attenuate chemi-

*Corresponding author: Environmental Research Group, Gregg Hall, University of New Hampshire, Durham, NH 03824. Phone: (603) 862-4334; Fax: (603) 862-3957; E-mail: kevin.gardner@unh.edu cals of concern, is an alternative to dredging or standard capping for in situ management of contaminated sites that is still in the development phases.

One of the sorbents that can be used in reactive caps to sequester HOCs effectively is activated carbon. Therefore, in our previous studies (Sharma, 2008) the performance of activated carbon was evaluated in the presence and absence of humic acid. Results showed significant reduction in the adsorption affinity for activated carbon due to the pore blockage effect caused by preloading activated carbon with humic acid. The reduction of adsorption affinity has significant implications for the design and performance of reactive caps, and for this reason it was desirable to evaluate additional sorptive media that may perform better in the presence of natural organic matter. Some studies have suggested that sorbents such as organoclays may have better performance in the presence of natural organics that can be found in sediments (Zhao and Vance, 1998).

Natural clays that have electrically charged and hydrophilic surfaces are ineffective in sequestration of HOCs from water (Jayens and Boyd, 1991; Dentel et al., 1998). Intercalation of organic cations in the interlayer spacing between the 
silica sheets increases this spacing and creates an organophilic zone for adsorption of HOCs and gives rise to the name organoclay. The hydrophobic characteristics of the clays can be altered by changing the properties of organic cation such as increasing the length of alkyl chain or varying the number or branches of the alkyl group (Pernyeszi et al., 2006).

Organoclays have been studied for soil remediation, groundwater purification, industrial waste water treatment, and oil spill remediation using batch systems (Dentel et al., 1998; Zhao and Vance, 1998; Ake et al., 2003; Wiles et al., 2005; Pernyeszi et al., 2006; Carmondy et al., 2007). Studies have shown good adsorption capacity of organoclays for chlorinated compounds such as trichloroethylene and polychlorophenols (Dentel et al., 1998; Zhao et al., 1998; Ake et al., 2003; Wiles et al., 2005; Pernyeszi et al., 2006; Carmondy et al., 2007). However, there are no studies available that demonstrate the affinity of PCBs for organoclays or the capacity of this sorbent material. Furthermore, high concentrations of dissolved organic carbon in sediment pore water (up to 0.6 to $7.5 \mathrm{~g} / \mathrm{L}$ according to Burgie, 2001) indicate the need to understand the effect of dissolved organic acids on sorption to organoclays. The two main objectives of this study were to determine the sorption affinity of PCBs for commercially available organoclays and to determine the effect of humic acid on the sorption affinity for organoclays to evaluate their applicability in contaminated sediment remediation.

\section{Materials and Methods}

\section{Kinetic experiments}

The kinetics of 2-chlorobiphenyl sorption on organoclays were investigated using CETCO (organo-bentonite; Hoffman Estates, IL) and Polymer Ventures (organo-attapulgite; Charleston, SC) organoclays. Experiments were conducted with $4 \mathrm{mg} \mathrm{L}^{-1}$ of 2-chlorobiphenyl for 15 days at $22^{\circ} \mathrm{C}$ in the presence and absence of humic acid. Experiments were conducted in separate $125 \mathrm{~mL}$ batch reactors of either deionized (DI) water or $1 \mathrm{~g} /$ L humic acid solution (prepared in DI water). PCBs were spiked in the system using a stock solution of PCBs prepared in ultrahigh purity methanol, which has been shown to have no measurable effect on sorption to organoclay (Lee et al., 2005). All the samples were continuously mixed at $150 \mathrm{rpm}$ on a rotary shaker for the length of the experiment prior to sampling by centrifugation and removal of supernatant.

Experiments were conducted in $125 \mathrm{~mL}$ Erlenmeyer Pyrex flasks with glass stoppers to minimize volatilization loss and sorption loss to the walls of the flask. Glassware was solvent/soapy water washed and properly rinsed with reverse osmosis (RO) water followed by drying in a muffle furnace at $500^{\circ} \mathrm{C}$ for $8 \mathrm{~h}$. Controls were prepared with each set of experiments to account for any loss of PCBs other than sorption on organoclays, and suitable recoveries from the controls were found. Experiments were run in duplicate and from each sample flask. Two subsamples were extracted to check for deviation in surrogate recovery; surrogate recoveries were all in the range of $70-120 \%$.

\section{Sorption isotherms}

Sorption isotherms for all selected PCB congeners were conducted in separate $125-\mathrm{mL}$ batch reactors of either DI water or $1-\mathrm{g} / \mathrm{L}$ humic acid solution and equilibrated for $48 \mathrm{~h}$.
The equilibration time was selected on the basis of the observed sorption kinetics of organoclay while also considering the retention time of contaminants in a thin reactive cap (selection of equilibration time is discussed further in the Results section). In all the batches the amount of organoclay was held constant $(0.1 \mathrm{~g})$ with varying concentrations of PCBs.

Preloading of organoclay with humic acid. Organoclays were preloaded with a stock solution of $1 \mathrm{~g} \mathrm{~L}^{-1}$ humic acid prepared using DI water and sodium salt of humic acid as obtained from Sigma-Aldrich (St. Louis, MO). To avoid biological growth in the system $100 \mathrm{mg} / \mathrm{L}$ sodium azide was added to the stock solution. Separate batches were prepared with a fixed amount of organoclay and $125 \mathrm{~mL}$ of humic acid stock solution in the Erlenmeyer flask. All the samples were thoroughly mixed at $150 \mathrm{rpm}$ on a rotary shaker for $48 \mathrm{~h}$ and were used as such for the experiments.

For all the experiments ultrahigh purity chemicals and gas chromatograph (GC)-grade solvents obtained from Fisher Scientific (Agawam, MA) were used. The PCB congeners 2-chlorobiphenyl, 2,2',5,5'-tetrachlorobiphenyl, 3,3',4,4'tetrachlorobiphenyl, 2,2' , $^{\prime}, 4^{\prime}, 5^{\prime}, 5^{\prime}$-hexachlorobiphenyl, and 3,3', 4,4',5,5'-hexachlorobiphenyl; internal standard 2,4,6-trichlorobiphenyl and surrogate standard 2,4,5,6-tetrachloro- $m$ xylene (TCMX) were purchased from Ultra Scientific (North Kingstown, RI) either in neat form or dissolved in hexane. The selection of PCB congeners was done on the basis of their coplanarity to represent the range of congeners from lower chlorinated to highly chlorinated with different coplanarity characteristics.

Organoclays. Three types of organoclays used in this study were obtained: PM 199 from CETCO; PS 86 from Polymer Ventures and Colorsorb $16 \times 40$ from Biomin Inc. (Ferndale, MI). The base clay used in CETCO and Biomin Inc. organoclays was bentonite, whereas in Polymer Ventures organoclay, attapulgite was used as a base clay (Fig. 1). Characteristics of all the three organoclays are provided in Table 1.

\section{Characterization of organoclays}

X-ray diffraction (XRD). XRD patterns were obtained on small-angle $X$-ray scattering (SAXS) $2 \mathrm{~m}-2 \mathrm{D}$ area detector using CuK $\alpha$ radiation with a wavelength of $1.5418 \AA$ at the Institute of Technology Characterization Facility, University of Minnesota. The instrument was operated at $44 \mathrm{kV}$ and $60 \mathrm{~mA}$ between $1.39^{\circ} 2 \theta$ at a step size of $0.01^{\circ} 2 \theta$ to obtain the interlayer $d$-spacing of organoclays (Table 1 ).

Thermogravimetric analysis (TGA). Differential thermal analysis (DTA) was performed on a TA Instruments model SDTQ600 to obtain organic matter content of all three organoclays (Table 1). Nitrogen flow was maintained at $100 \mathrm{~mL}$ $\min ^{-1}$ with oxygen supply at $242 \mathrm{~mL} \mathrm{~min}^{-1}$ from 28 to $1,000^{\circ} \mathrm{C}$ with a heating rate of $10^{\circ} \mathrm{C} \mathrm{min}-1$.

\section{Sample analysis}

Sample extraction. The vial liquid-liquid extraction method was used for the extraction of supernatant of each sample into hexane with TCMX as a surrogate standard. Ten milliliters of surrogate solvent (prepared in hexane) with $20 \mathrm{~mL}$ of sample were taken into a $40 \mathrm{~mL}$ vial sealed with Teflon ${ }^{\circledR}$-lined screw caps. All the samples were extracted in 

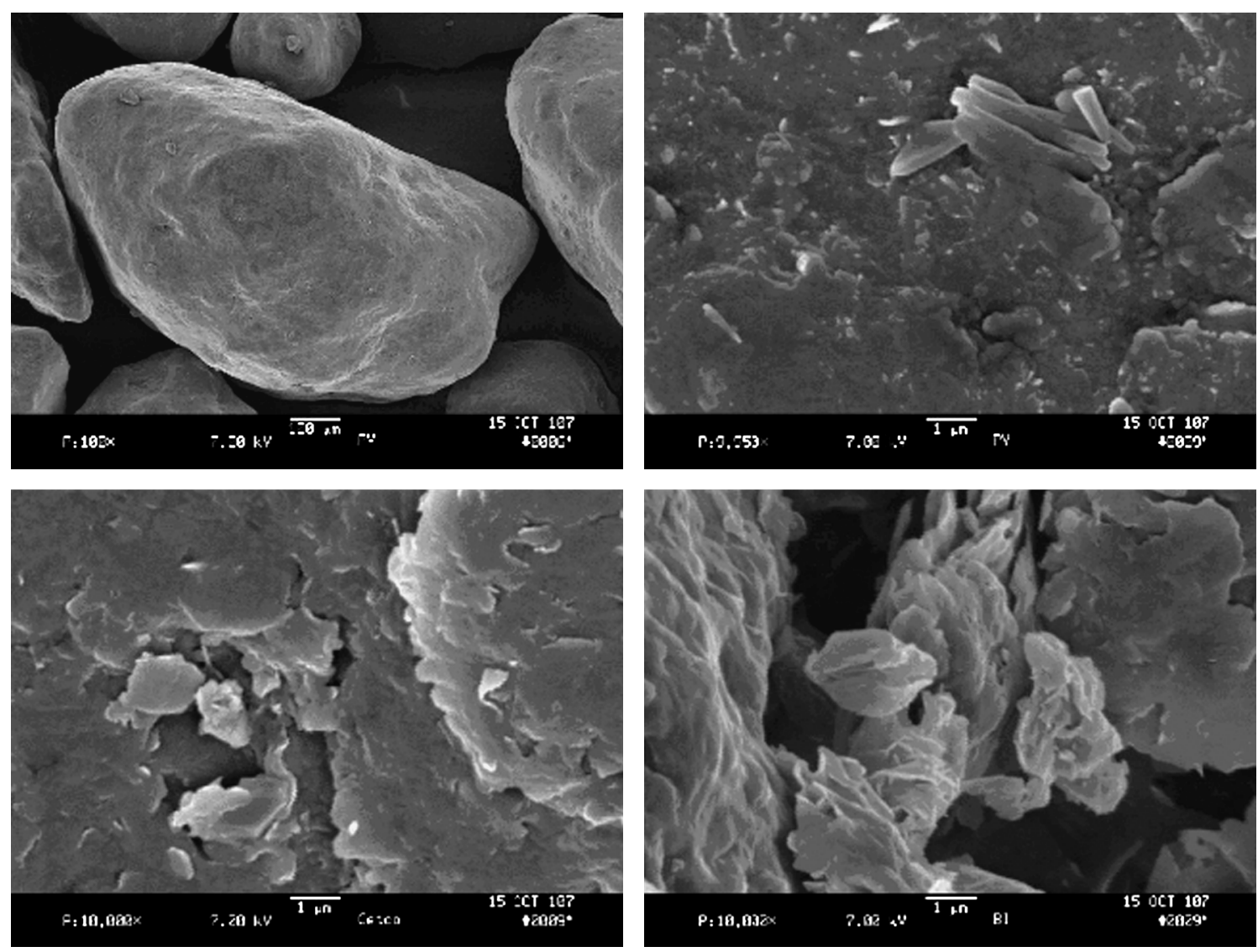

FIG. 1. Scanning electron micrographs of organoclays: Polymer Ventures $(100 \times$ original magnification, top left; $10 \mathrm{~K} \times$ original magnification, top right); CETCO $(10 \mathrm{~K} \times$ original magnification, bottom left) and Biomin Inc. $(10 \mathrm{~K} \times$ original magnification, bottom right).

duplicate to determine the variation in extraction procedure. The vials were shaken vigorously for $30 \mathrm{~s}$ three times at intervals of $30 \mathrm{~s}$ each and then stored for at least for $24 \mathrm{~h}$ at $4^{\circ} \mathrm{C}$ to allow proper extraction. The extracts were passed through sodium sulfate to remove water. GC vials were then prepared with filtered extracts and addition of 2,4,6-trichlorobiphenyl as an internal standard.

Gas chromatography/mass spectrometry. All the extracts were analyzed using the internal standard method on
Varian CP3800 Gas Chromatograph (GC)/Saturn 2200 Ion Trap Mass Spectrometer (MS) with a CP8400 Auto Sampler (Varian, Palo Alto, CA) with one readback and one blank run after every eighth sample for each run. The concentration of PCB in blanks was nondetectable. The GC column used was a DB-5 type capillary column (Varian Factor Four VF-5 ms), $30 \mathrm{~m}$ long, $0.25 \mathrm{~mm}$ i.d., and $0.5-\mu \mathrm{m}$ thick. The ion-trap was operated in selected scan mode (MS/MS) for each PCB congener. The column oven temperature was programmed at $40^{\circ} \mathrm{C}$ with hold time of $2 \mathrm{~min}$ followed by a temperature ramp

Table 1. Characteristics of Organoclays

\begin{tabular}{|c|c|c|c|}
\hline & CETCO organoclay & Polymer Ventures organoclay & Biomin Inc. organoclay \\
\hline Base clay & Bentonite & Attapulgite & Bentonite \\
\hline BET surface area $\left(\mathrm{m}^{2} / \mathrm{g}\right)$ & 0.3225 & 16.7294 & 0.1872 \\
\hline Interlayer spacing $\left(\mathrm{d}_{001}\right.$ spacing $\left.\mathrm{A}^{\prime}\right)$ & $35.74(2 \theta=2.47)$ & $35.85(2 \theta=2.46)$ & $37.89(2 \theta=2.33)$ \\
\hline$\%$ Organic matter & 19.10 & 10.54 & 26.95 \\
\hline Inorganic cations ${ }^{\mathrm{a}}(\mathrm{ppm})$ & & & \\
\hline Calcium (Ca) & 967.2 & 750.8 & 682.2 \\
\hline Magnesium (Mg) & 175.0 & 230.0 & 169.0 \\
\hline Potassium $(\mathrm{K})$ & 79.0 & 337.0 & 46.0 \\
\hline Phosphorus (P) & 1.0 & 12.0 & 1.0 \\
\hline Estd. $\mathrm{CEC}^{\mathrm{a}}(\mathrm{mEq} / 100 \mathrm{~g})$ based on inorganic cations & 6.50 & 6.53 & 4.94 \\
\hline
\end{tabular}

aAnalyzed by University of New Hampshire Cooperative Extension.

Estd. CEC, estimated cation exchange capacity. 
up to $184^{\circ} \mathrm{C}$ at the rate of $12^{\circ} \mathrm{C} / \mathrm{min}$ and then to $280^{\circ} \mathrm{C}$ at the rate of $4^{\circ} \mathrm{C} / \mathrm{min}$ with a final hold time of $2 \mathrm{~min}$. The surrogate recoveries were all in the range of $70-120 \%$ using this internal standard method.

\section{Results and Discussions}

\section{Kinetics}

The kinetic experiments were conducted to estimate the equilibration time for adsorption of 2-chlorobiphenyl on two compositions of organoclays having different base clays (CETCO, a bentonite-based organoclay, and Polymer Ventures, an attapulgite-based organoclay). The results showed approximately the same time was required to reach equilibrium for both types of organoclays (Fig. 2). The sorption kinetics of 2-chlorobiphenyl were investigated in the presence and absence of humic acid. For this purpose both types of organoclays were preloaded with humic acid prior to the spiking of 2-chlorobiphenyl in the system. Equilibrium was reached at approximately $48 \mathrm{~h}$ for bare organoclays, but the presence of humic acid significantly decreased the sorption kinetics. This may be due to the slow diffusivity of 2-chlorobiphenyl into the interlayer spacing of organoclays in

A

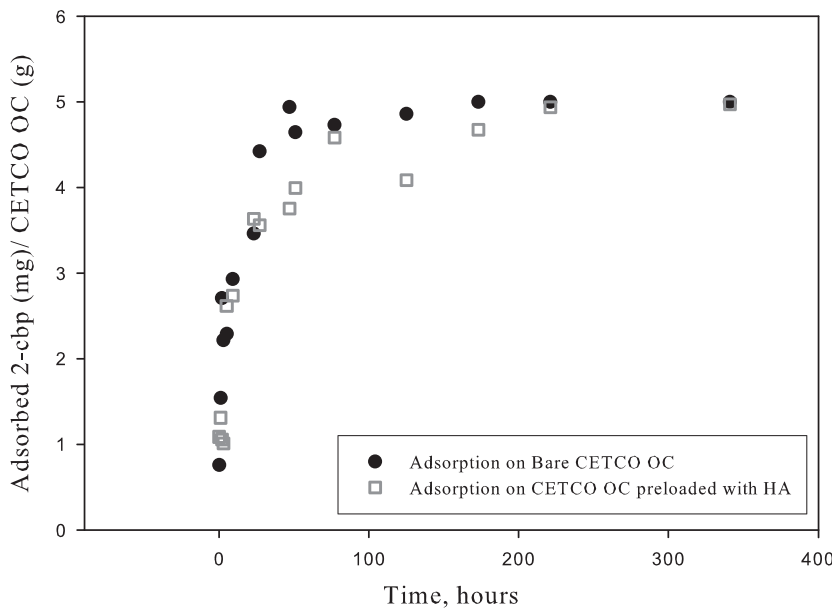

B

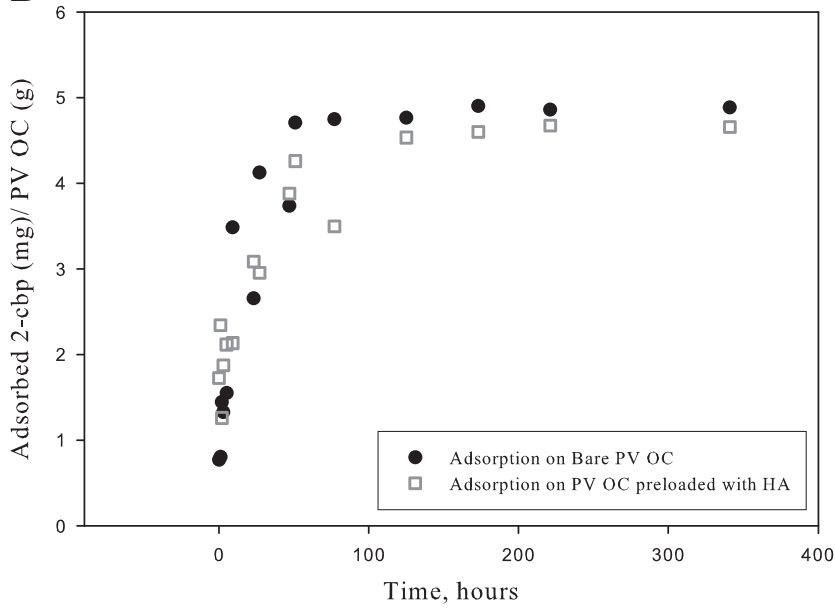

FIG. 2. Kinetics of sorption of 2-chlorobiphenyl on organoclays (OCs): (A) CETCO organoclay (B) Polymer Ventures (PV) organoclay. HA, humic acid. the presence of humic acid molecules that can block the path of the contaminants due to hydrophobic interactions with organophilic outer layers of organoclays. This is conceptually similar to the well-established phenomenon of pore blockage by humic acid molecules on activated carbon; in this case, it is hypothesized that humic acid blocks the access to the clay interlayers, which are on the order of $35 \AA$ in size (Table 1 ).

Kinetics were important to characterize not only for the conduct of isotherm experiments but also for understanding the practical application of a thin reactive cap; studies conducted at Anacostia River for demonstration of specific discharge and tidal heights showed the average specific discharge of sediment pore water to the overlying water column was $5 \mathrm{~cm} /$ day (Draft Data Report, 2006). This underscores the significance of understanding adsorption kinetics, as residence time in a thin layer cap may be significantly less that $24 \mathrm{~h}$. Given that the residence time of porewater moving through a thin reactive cap can be as little as $4.8 \mathrm{~h}$ (for a $5-\mathrm{cm} /$ day flux and 1-cm thick cap), a decision had to made for how long to equilibrate samples when conducting isotherm experiments ( $48 \mathrm{~h}$ was used in the experiments discussed below).

\section{Isotherms}

The sorption affinity of a range of PCB congeners (Table 2) for three commercially available organoclays was evaluated in the presence and absence of humic acid. The effect of humic acid was evaluated by preloading organoclay with humic acid prior to PCB spiking and by spiking humic acid in the system after PCB adsorption on organoclay to investigate whether high humic acid concentrations would cause appreciable desorption of PCBs. Preloading was estimated to simulate the typical site conditions where sorbents might come across very high concentrations of natural organics that can affect the sorption affinity of sorbents for target organic contaminants. Desorption studies simulated the long-term exposure of these sorbents to organic acids after adsorption of contaminants as well as to determine the reversibility of the system.

Adsorption affinity of PCBs for the sorbents was evaluated by using a linear fit and a nonlinear Freundlich fit for the data (Table 3). The linear fit is provided here to enable straightforward comparison of sorption affinities, although the data are clearly nonlinear in nature. The Freundlich model used is described as:

$$
q_{e}=K_{F}\left(C_{e}^{(1 / n)}\right)
$$

where $q_{e}$ is the mass of contaminant adsorbed on the sorbent $(\mathrm{mg} / \mathrm{g}), K_{F}$ is the Freundlich isotherm constant, $C_{e}$ is the aqueous phase concentration $(\mathrm{mg} / \mathrm{L})$, and $1 / n$ is the dimensionless Freundlich exponent. The value of the Freundlich exponent was used to characterize the nature of adsorption of PCBs on organoclays. The nonlinearity of isotherms was estimated based on $(1 / n)$ values; the trend is considered to be favorable for $(1 / n)<1$ and unfavorable for $(1 / n)>1$.

Sorption of 2-chlorobiphenyl was evaluated for all the three organoclays including CETCO organoclay, Polymer Ventures organoclay, and Biomin Inc. organoclay (Fig. 3A-C). Figure 3 shows a significant decrease in adsorption affinity due to humic acid preloading on all three organoclays for sorption of 2-chlorobiphenyl; no desorption was noticed for CETCO and Biomin Inc. organoclays, and slight desorption was noticed in 
Table 2. Details of Selected Polychlorinated Biphenyl Congeners Used in the Study

\begin{tabular}{lccc}
\hline PCB congener & $\begin{array}{c}\text { Solubility limit } \\
\text { in water }(p p m)^{\mathrm{a}}\end{array}$ & $\begin{array}{c}\text { Log } \\
\mathrm{K}_{O W v} \mathrm{~b}\end{array}$ & $\begin{array}{c}\text { Log } \\
\mathrm{K}_{D O C}\end{array}$ \\
\hline 2-cbp & 4.0 & 4.7 & $3.63^{\mathrm{b}}$ \\
$2,2^{\prime}, 5,5^{\prime}-\mathrm{tPCB}$ & 0.26 & 5.9 & $4.6^{\mathrm{c}}$ \\
$3,3^{\prime}, 4,4^{\prime}-\mathrm{tPCB}$ & 0.26 & 5.9 & - \\
$2,2^{\prime}, 4,4^{\prime}, 5,5^{\prime}-\mathrm{hPCB}$ & 0.038 & 6.7 & $5.3^{\mathrm{c}}$ \\
$3,3^{\prime}, 4,4^{\prime}, 5,5^{\prime}-\mathrm{hPCB}$ & 0.038 & 6.7 & - \\
\hline
\end{tabular}

${ }^{a}$ Erickson, 1997.

b Butcher et al., 2004.

'Poerschmann et al., 1999.

PCB, polychlorinated biphenyl.

the case of Polymer Ventures organoclay when humic acid was postloaded. The adsorption coefficients $\left(K_{d}\right)$ based on a linear fit of the data showed greater affinity in the case of bare CETCO organoclay compared to the other two compositions, but the sorption affinity of all organoclays for 2-chlorobiphenyl was found to be less compared to coconut shell activated carbon as evaluated in the previous studies (Table 3) (Sharma, 2008). A 78\% reduction in the sorption affinity (based on $K_{d}$ values) for CETCO organoclay resulted from preloading with humic acid (Table 3 ). The reduction was about $60 \%$ for Polymer Ventures organoclay and about $45 \%$ for Biomin Inc. organoclay.

A statistical analysis was conducted to evaluate the performance of the three compositions of organoclays for the sorption of 2-chlorobiphenyl. The model (Model 1) was developed on the Fit model platform using software JMP ${ }^{\circledR} 7$. The hypothesis of this model was that there was a difference in the performance of the three organoclays for 2-chlorobiphenyl sorption in the presence and absence of humic acid. The three factors considered in this model were: type of organoclay, loading rate of 2-chlorobiphenyl, and treatment effects (preloading/postloading of humic acid) on organoclay. The regression analysis was done using a full factorial design with these three factors. According to the analysis of variance (ANOVA) the $p$-value was $<0.0001$; therefore, the hypothesis of the model was significant: all three factors were significant. The $F$-test was performed on each term in the model including the main effects and interaction terms to determine the significance of the factors based on a $p$-value $<0.05$. The leastsquare means of adsorbed concentration of 2-chlorobiphenyl on all organoclays were plotted against the treatment effects (preloading/desorptionof humic acid) and are shown in Fig. 4. There was no significant difference in the performance of bare CETCO and Polymer Ventures organoclays; however, the sorption affinity for Biomin Inc. organoclay was less. The preloading of organoclays with humic acid significantly reduced their sorption affinity (Fig. 4). No desorption was found in the case of CETCO and Biomin Inc. organoclay but slight desorption was observed in the case of Polymer Ventures organoclay. Interestingly, there appears to be some enhancement of adsorption when humic acid was added after PCBs were allowed to equilibrate for $48 \mathrm{~h}$ (Fig. 3A and C). This effect is hypothesized to be a result of the sorption of aqueous humic acid-PCB complexes. Although these complexes would also adsorb in the experiments where humic acid was preloaded on the organoclay, the blockage of adsorption sites by humic acid molecules (prior to PCB adsorption at those sites) is a more significant effect, resulting in the net reduction in observed adsorption affinity.

Table 3. Adsorption Isotherm Coefficients and Freundlich Isotherm Constants for Different Types of Sorbents for Selected Polychlorinated Biphenyl Congeners

\begin{tabular}{|c|c|c|c|c|c|c|}
\hline & \multirow{2}{*}{\multicolumn{2}{|c|}{$\begin{array}{c}\text { Adsorption isotherm constants } \\
\mathrm{K}_{\mathrm{d}}\left(L g^{-1}\right)\end{array}$}} & \multicolumn{4}{|c|}{ Freundlich isotherm constants } \\
\hline & & & \multicolumn{2}{|c|}{$\mathrm{K}_{\mathrm{f}}\left(m g^{[1-(1 / \mathrm{n})]} L^{(1 / \mathrm{n})} g^{-1}\right)$} & \multicolumn{2}{|c|}{$1 / \mathrm{n}$} \\
\hline & $\begin{array}{l}\text { Adsorption } \\
\text { on bare OC }\end{array}$ & $\begin{array}{c}\text { Preloading } \\
\text { effect }\end{array}$ & $\begin{array}{l}\text { Adsorption } \\
\text { on bare OC }\end{array}$ & $\begin{array}{l}\text { Preloading } \\
\text { effect }\end{array}$ & $\begin{array}{l}\text { Adsorption } \\
\text { on bare OC }\end{array}$ & $\begin{array}{c}\text { Preloading } \\
\text { effect }\end{array}$ \\
\hline \multicolumn{7}{|l|}{ CETCO OC } \\
\hline 2-cbp & 7.8 & 1.7 & 7.6 & 1.2 & 1.6 & 1.3 \\
\hline $2,2^{\prime}, 5,5^{\prime}-\mathrm{tPCB}$ & 11.5 & 2.7 & 7.0 & 2.1 & 0.8 & 0.9 \\
\hline $3,3^{\prime}, 4,4^{\prime}-\mathrm{tPCB}$ & 7.9 & 0.5 & - & 0.4 & 4.6 & 0.7 \\
\hline $2,2^{\prime}, 4,4^{\prime}, 5,5^{\prime}-\mathrm{hPCB}$ & 228.2 & 30.5 & 20.2 & 7.3 & 0.6 & 0.6 \\
\hline $3,3^{\prime}, 4,4^{\prime}, 5,5^{\prime}-\mathrm{hPCB}$ & 150.0 & 9.2 & 1.3 & - & 0.3 & 2.2 \\
\hline \multicolumn{7}{|l|}{ PV OC } \\
\hline $2-\mathrm{cbp}$ & 4.3 & 1.7 & 5.6 & 1.7 & 0.6 & 1.0 \\
\hline $2,2^{\prime}, 5,5^{\prime}-\mathrm{tPCB}$ & 53.7 & 2.1 & - & 1.8 & 2.6 & 0.9 \\
\hline \multicolumn{7}{|l|}{$\mathrm{BI} \mathrm{OC}$} \\
\hline 2-cbp & 1.9 & 1.0 & 4.9 & 3.0 & 0.3 & 0.3 \\
\hline \multicolumn{7}{|l|}{ Coconut shell AC } \\
\hline $2-c b p$ & 12.62 & 1.38 & 7.00 & 0.95 & 0.33 & 1.42 \\
\hline $2,2^{\prime}, 5,5^{\prime}-\mathrm{tPCB}$ & 16.50 & 2.96 & 2.34 & 2.46 & 0.43 & 0.90 \\
\hline $3,3^{\prime}, 4,4^{\prime}-\mathrm{tPCB}$ & 9.98 & 4.12 & 4.11 & 10.83 & 0.60 & 1.51 \\
\hline $2,2^{\prime}, 4,4^{\prime}, 5,5^{\prime}-\mathrm{hPCB}$ & 35.98 & 11.62 & 4.44 & 8.26 & 0.39 & 0.85 \\
\hline $3,3^{\prime}, 4,4^{\prime}, 5,5^{\prime}-\mathrm{hPCB}$ & 17.85 & 12.21 & 18.75 & 35.59 & 1.00 & 1.37 \\
\hline \multicolumn{7}{|l|}{ Coal-based AC } \\
\hline $2,2^{\prime}, 5,5^{\prime}-\mathrm{tPCB}$ & 6.34 & 3.35 & 5.88 & 2.10 & 0.92 & 0.77 \\
\hline
\end{tabular}

BI, Biomin Inc.; AC, activated carbon. 


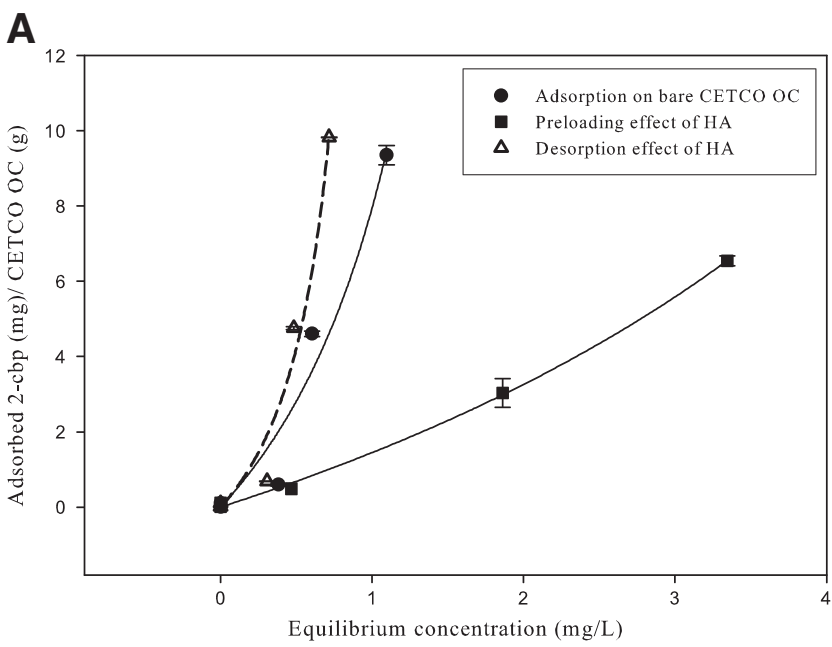

B
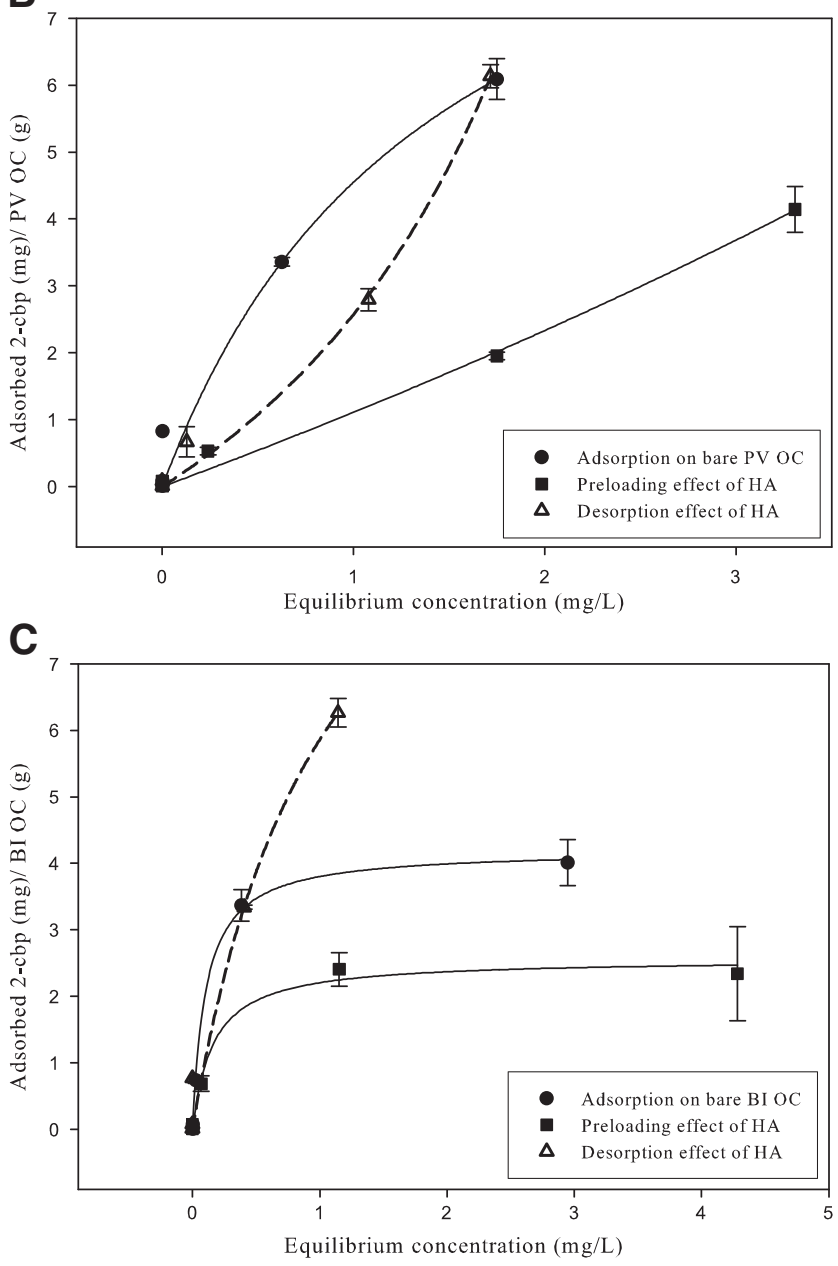

FIG. 3. Freundlich adsorption isotherms for 2chlorobiphenyl in the presence and of humic acid (A) CETCO organoclay, (B) Polymer Ventures organoclay, (C) Biomin Inc. organoclay.

$2,2^{\prime}, 5,5^{\prime}$-Tetrachlorobiphenyl sorption isotherms were obtained using CETCO and Polymer Ventures organoclay (Fig. $5 \mathrm{~A}-\mathrm{B}$ ). Based on the $K_{d}$ values (Table 3 ), the sorption affinity of Polymer Ventures organoclay was higher than CETCO organoclay but preloading with humic acid significantly re-

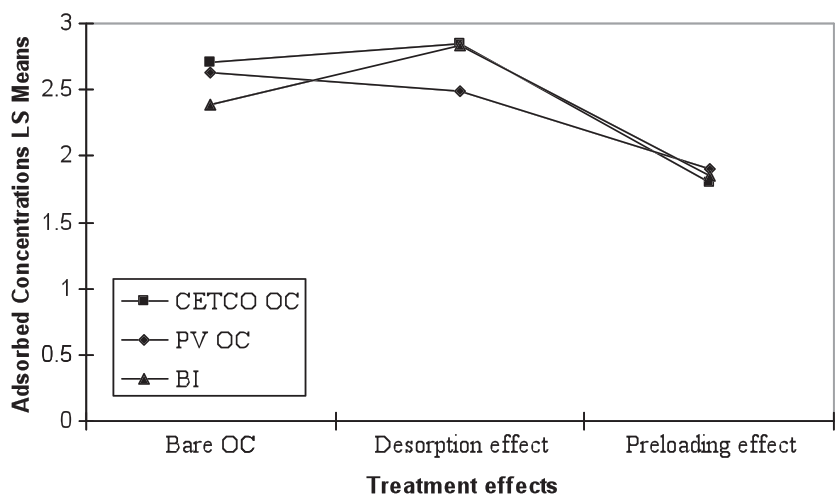

FIG. 4. Least-square means plot for adsorption of 2chlorobiphenyl on all the three organoclays.

duced the sorption affinity for both types of organoclays. The reduction was found to be $76 \%$ for CETCO organoclay and $96 \%$ in the case of Polymer Ventures organoclay (Table 3 ). The performance of these two organoclays for sorption of $2,2^{\prime}, 5,5^{\prime}-$ tetrachlorobipheny was also analyzed statistically using a Fit model platform in $\mathrm{JMP}^{\circledR}$ 7. The model (Model 2) was developed based on the same hypothesis as used in the first statistical model: that the performance of CETCO and Polymer Ventures organoclays are different for $2,2^{\prime}, 5,5^{\prime}$ tetrachlorobiphenyl sorption. In this model three factors were taken into consideration: type of organoclay, treatment on organoclay (humic acid pre- or postloading) and loading rate of 2,2',5,5'-tetrachlorobiphenyl. The full factorial design was developed with all three factors and the quadratic term for loading rate. According to ANOVA, the $p$-value obtained was $<0.0001$; therefore, the hypothesis of Model 2 was significant. The Student's $t$ at $\alpha=0.05$ showed the performance of bare Polymer Ventures organoclay to be better than that of CETCO organoclay. The preloading of humic acid was found to be more significant for Polymer Ventures organoclay, but desorption effects were found to be similar for both materials (Table 4). The analysis demonstrates that CETCO organoclay performed better than Polymer Ventures organoclay for $2,2^{\prime}, 5,5^{\prime}$-tetrachlorobiphenyl in the presence of preloaded humic acid.

The sorption affinity for CETCO organoclay was further evaluated for coplanar 3, 3',4,4'-tetrachlorobiphenyl and two hexachloro-congeners: one noncoplanar and one coplanar (Figs. 5A, 5C, and 6). Adsorption coefficients $\left(K_{d}\right)$ of the noncoplanar congeners were found to be higher compared to their coplanar isomers for both tetra- and hexachlorobiphenyls (Table 3). The reduction in sorption affinity from preloading of humic acid was found to be more pronounced for coplanar congeners but desorption was found to be similar for both noncoplanar and coplanar congeners. There was a 93\% reduction in performance of CETCO organoclay for $3,3^{\prime}, 4,4^{\prime}$ tetrachlorobiphenyl, $86 \%$ for $2,2^{\prime}, 4,4^{\prime}, 5,5^{\prime}$-hexachlorobiphenyl and $93 \%$ for $3,3^{\prime}, 4,4^{\prime}, 5,5^{\prime}$-hexachlorobiphenyl (based on the change in linear adsorption coefficients). It is interesting to note that in previous studies, the reduction in performance of activated carbon was noticed to be greater for noncoplanar congeners where as the opposite is true for CETCO organoclay (Sharma, 2008). The sorption affinity for CETCO organoclay was also found to be highest for highly chlorinated congeners and the order was: hexachlorobiphenyl > 
A

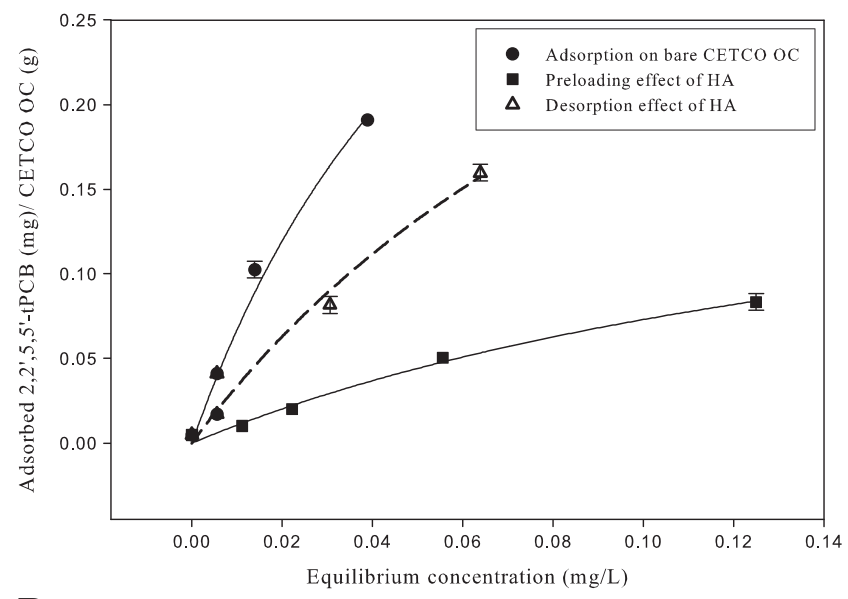

B

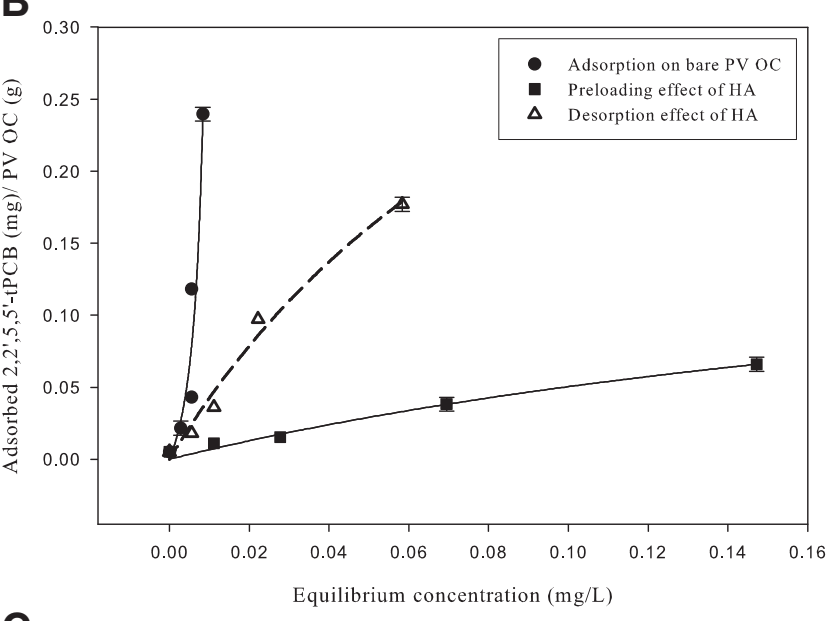

c

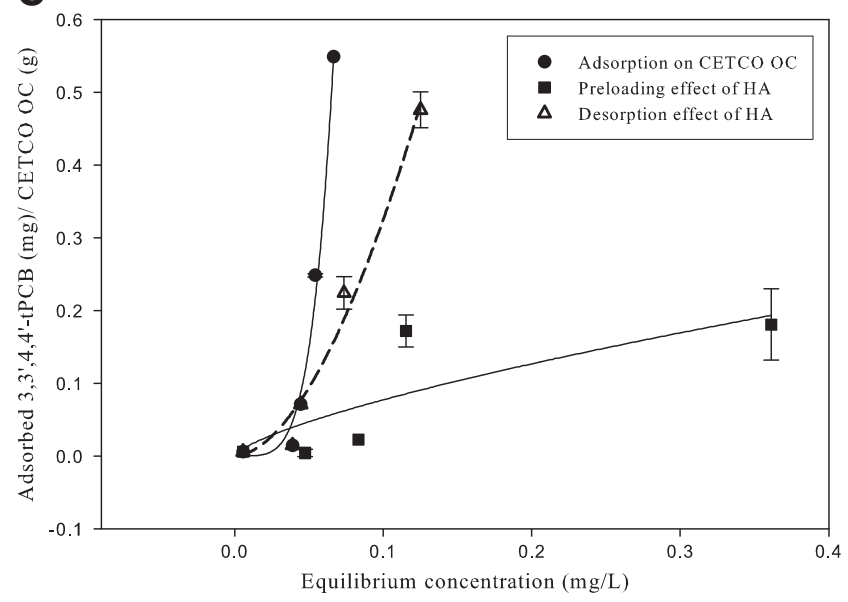

FIG. 5. Freundlich adsorption isotherms for adsorption of tetrachlorobiphenyl in the presence and the absence of humic acid (A) 2,2',5,5'-tPCB adsorption on CETCO organoclay, (B) $2,2^{\prime}, 5,5^{\prime}$ - $\mathrm{PCB}$ adsorption on Polymer Ventures organoclay, (C) 3,3', 4, $4^{\prime}$-tPCB adsorption on CETCO organoclay.

tetrachlorobiphenyl $\geq$ monochlorobiphenyl, which is similar to the behavior of activated carbon (Table 3 ).

A statistical analysis was done using JMP ${ }^{\circledR} 7$ and a model (Model 3) was developed to evaluate the performance of CETCO organoclay for tetra- and hexachlorobiphenyl based

Table 4. Least Square Means Differences Student's $T$ AT $\alpha=0.050$ AND $T=2.119$ for Comparing Performance of CETCO and Polymer Ventures Organoclays for Adsorption of 2,2',5,5'-TPCB IN the Presence OF Humic ACID

Level $^{\mathrm{a}} \quad$ Least square mean

PV, bare OC

CETCO, bare OC

PV, Desorption effect CETCO, desorption effect CETCO, preloading effect PV, preloading effect

${ }^{a}$ Levels not connected by same letter are significantly different.

on the degree of chlorination as well as coplanarity of the congeners in the presence and absence of humic acid. The hypothesis of this model was that the degree of chlorination of PCBs and their coplanarity affect the sorption affinity for CETCO organoclay. The full factorial design was developed for regression analysis of the model with the three factors and the quadratic term for loading rate. The $p$-value obtained was

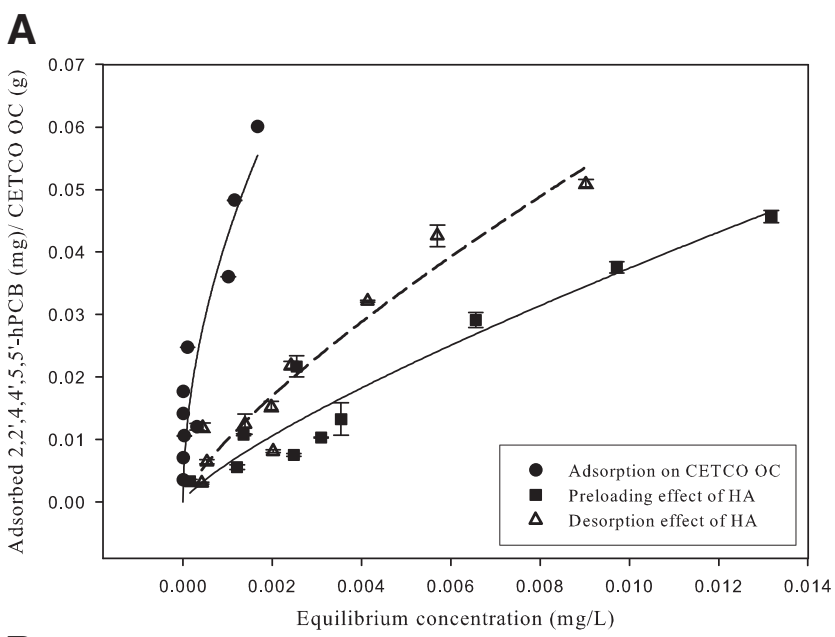

B

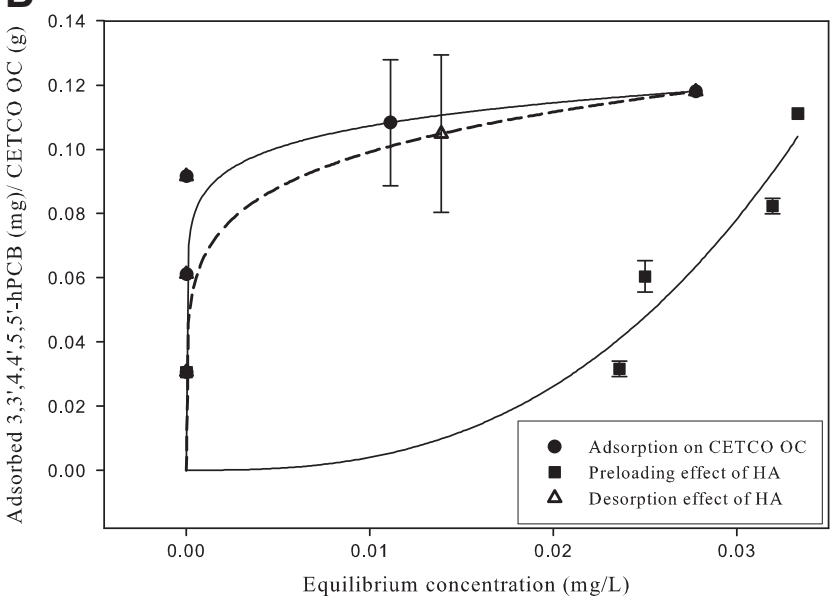

FIG. 6. Freundlich adsorption isotherms for adsorption of hexachlorobiphenyl on CETCO organoclay in presence and absence of humic acid (A) 2,2',4,4',5, $5^{\prime}-\mathrm{hPCB}$, (B) $3,3^{\prime}, 4,4^{\prime}, 5,5^{\prime}-$ hPCB. 


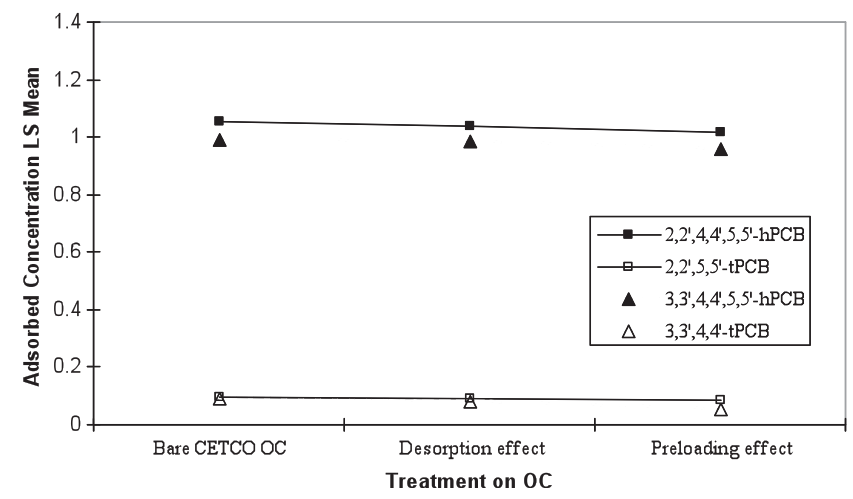

FIG. 7. Least-square means plot for adsorption of tetra- and hexachlorinated congeners on CETCO organoclay.

$<0.0001$ in ANOVA; therefore, the degree of chlorination, coplanarity, and presence/absence of humic acid were all significant. The least-square means plot was obtained by plotting least square means of adsorbed concentration of all PCB congeners against the treatment effects (preloading/ desorption with humic acid) on CETCO organoclay (Fig. 7). The preloading effect was found to be more pronounced in the case of coplanar congeners compared to their noncoplanar isomers, and desorption effects were not substantial in any case. It was also observed that the adsorption affinity for CETCO organoclay was higher for hexachlorobiphenyls than for tetrachlorobiphenyls for all the treatment effects.

\section{Summary}

Adsorption of a range of PCB congeners to three commercially available organoclays was conducted to investigate the sorption kinetics (for 2-chlorobiphenyl) and sorption affinity for four additional congeners (a coplanar tetrachlorobiphenyl, noncoplanar tetrachlorobiphenyl, coplanar hexachlorobiphenyl, and noncoplanar hexachlorobiphenyl). Experiments were conducted with organoclays that had been preloaded with humic acid for $48 \mathrm{~h}$, with bare organoclay, and with humic acid spiked into bare organclay experiments after equilibration of bare organoclay with PCBs to investigate propensity for desorption from these materials. Experimental results showed equilbrium was achieved for bare organoclays in $48 \mathrm{~h}$, whereas organoclays preloaded with humic acid equilibrated in approximately $200 \mathrm{~h}$. In desorption studies 2chlorobiphenyl did not show any effect from humic acid added in the system after its adsorption but there was some effect in the case of tetra- and hexachlorinated congeners. In contrast to characteristics typical of activated carbon, coplanar congeners studied were more significantly affected by humic acid preloading than the noncoplanar isomers.

\section{Acknowledgments}

This research is a part of dissertation submitted to the Graduate School of the University of New Hampshire as a part of the requirements for completion of a doctoral degree. The authors are grateful to the Strategic Environmental Research and Development Program (SERDP) for funding the project. Thanks to the University of New Hampshire Cooperative Extension Program for basic analysis of organoclays. Thanks to the Institute of Technology Characterization
Facility, University of Minnesota, for SAXS analysis. We would like to extend our thanks to CETCO, Polymer Ventures, and Biomin Inc. for providing organoclays and helping us with our queries about the materials.

\section{Author Disclosure Statement}

The authors declare that no conflicting financial interests exist.

\section{References}

Ake, C.L., Wiles, M.C., Huebner, H.J., McDonald, T.J., Cosgriff, D., Richardson, M.B., Donnelly, K.C., and Phillips, T.D. (2003). Porous organoclay composites for the sorption of polycyclic aromatic hydrocarbons and pentachlorophenol from groundwater. Chemosphere 51, 835.

ATSDR 2007. (2007). CERCLA Priority List of Hazardous Substances That Will Be Subject of Toxicological Profiles and Support Document. Atlanta, GA: U.S. Department of Health and Human Services, Agency for Toxic Substances and Disease Registry, Division of Toxicology (in cooperation with the U.S. EPA).

Burgie, D.J. (2001). Dissolved organic matter in Chesapeake Bay sediment pore waters. Organic Geochem. 32, 487.

Butcher, J.B., and Garvey, E.A. (2004). PCB Loading from sediment in the Hudson River: Congener signature analysis of pathways. Environ. Sci. Technol. 38, 3232.

Carmody, O., Frost, R., Xi, Y., and Kokot, S. (2007). Adsorption of hydrocarbons on organo-clays-Implications for oil spill remediation. J. Colloid Interface Sci. 305, 17.

Dentel, S.K., Jamarah, A.I., and Sparks, D.L. (1998). Sorption and cosorption of 1,2,4-trichlorobenzene and tannic acid by organo-clays. Water Res. 32, 3689.

Draft Data Report. (2006). Trident and UltraSeep Month 30 PostCapping Evaluation for the Apatite Cap Test Area on the Anacostia River. Washington, D.C. December 2006, submitted to Environmental Research Group, University of New Hampshire, Durham, NH by Coastal Monitoring Associates, San Diego, CA.

Erickson, M.D. (1997). Analytical Chemistry of PCBs, 2nd ed. Boca Raton, FL: Lewis Publishers.

Jayens, W.F., and Boyd, S.A. 1991. clay mineral type and organic compound sorption by hexadecyltrimethyammoniumExchanges clays. Soil Sci. Soc. Am. J. 55, 43.

Lee, S.Y., Kim, S.J., Chung, S.Y., and Jeong, C.H. (2005). Sorption of hydrophobic organic compounds onto organoclays. Chemosphere 55, 781.

National Research Council (NRC). (2001). A Risk-Management Strategy for PCB-Contaminated Sediments. Washington, DC: National Research Council Report; National Academy Press.

National Research Council (NRC). (2003). Bioavailability of Contaminants in Soils and Sediments: Processes, Tools, and Applications. Washington, DC: National Academies Press, Washington, DC. Available at: http://www.nap.edu/openbook .php?isbn $=0309086256$.

Pernyeszi, T., Kasteel, R., Witthuhn, B., Klahre, P., Vereecken, H., and Klumpp, E. (2006). Organoclays for soil remediation: Adsorption of 2,4-dichlorobiphenyl on organoclay/aquifer material mixtures studied under static and flow conditions. Appl. Clay Sci. 32, 179.

Poerschmann, J., Kopinke, F.-D., Plugge, J., and Georgi, A. (1999). Interaction of organic chemicals (PAHs, PCB, triazines, nitroaromatics and organotin compounds) with dissolved humic organic matter. In G. Davies and E.A. Ghabbour (Eds.), Understanding Humic Substances: Advanced Methods, Properties and Applications, Cambridge: Royal Society of Chemistry, p. 223. 
Sharma, B. (2008). Evaluation of reactive cap sorbents for in-situ remediation of contaminated sediments. PhD. Dissertation, University of New Hampshire.

Wiles, M.C., Huebner, H.J., McDonald, T.J., Donnelly, K.C., and Phillips, T.D. (2005). Matrix-immobilized organoclay for the sorption of polycyclic aromatic hydrocarbons and pentachlorophenol from groundwater. Chemosphere 59, 1455.

Zhao, H., and Vance, G.F. (1998). Sorption of trichloroethylene by organoclays in the presence of humic substances. Water Res. 32,3710 . 
